\title{
Recognition of stroke-related knowledge among community residents and the improvement after intensive health education: a cross-sectional study
}

Xuemin Zhong, Jian Wang, Lanying He and Ronghua Xu*

\begin{abstract}
Background: The high morbidity, mortality, and disability rates of stroke constitute a heavy burden to the society. The level of understanding about stroke warning symptoms and first aid systems among community residents was generally low. The aim of our work is to investigate stroke-related knowledge in community residents of Jinjiang district of Chengdu and to raise public awareness about stroke through an intensive educational program.
\end{abstract}

Methods: Nine communities in Jinjiang district were sampled and a questionnaire about stroke-related knowledge was applied before and after stroke educational activities. We analyzed the impact of such activities in stroke recognition and management.

Results: We collected 1685 valid questionnaires. The awareness about stroke risk before educational activities was $11.4 \%$. The recognition of stroke warning signs among community residents was $29.8-59.5 \%$. Among them, the recognition of major signs, such as limb weakness, language disorder, and imbalance was more than $50 \%$. When faced with five stroke warning signs, the proportion of participants who chose to make an emergency call was $41.5 \%$. Less than $10 \%$ of the participants chose to consult a doctor, take medicine, or wait. After strengthening publicity and educational activities regarding stroke, there was a significant improvement in the identification of stroke risk factors, warning signs, and stroke management. The percentage of participants who chose to make an emergency call increased from 53.2 to $82.7 \%$.

Conclusions: The knowledge about stroke among community residents in Jinjiang District of Chengdu was low. Strengthening publicity and educational activities may raise awareness about stroke prioritizing call emergency after the onset of stroke signs.

Keywords: Stroke, Community residents, Warning symptoms, Intensive education

* Correspondence: 2234117052@qq.com

Department of Neurology, The Second People's Hospital of Chengdu,

Chengdu, Sichuan, China

C C The Author(s). 2020 Open Access This article is licensed under a Creative Commons Attribution 4.0 International License, which permits use, sharing, adaptation, distribution and reproduction in any medium or format, as long as you give appropriate credit to the original author(s) and the source, provide a link to the Creative Commons licence, and indicate if changes were made. The images or other third party material in this article are included in the article's Creative Commons licence, unless indicated otherwise in a credit line to the material. If material is not included in the article's Creative Commons licence and your intended use is not permitted by statutory regulation or exceeds the permitted use, you will need to obtain permission directly from the copyright holder. To view a copy of this licence, visit http://creativecommons.org/licenses/by/4.0/ The Creative Commons Public Domain Dedication waiver (http://creativecommons.org/publicdomain/zero/1.0/) applies to the data made available in this article, unless otherwise stated in a credit line to the data. 


\section{Background}

Stroke is a serious disease with the highest disability rate. Its high morbidity, mortality, and disability rates constitute a heavy burden and a great source of pain to the society, families, and patients [1]. The number of new stroke patients in China is about 2 million every year, of which $70-80 \%$ is unable to live independently due to disability [2]. At present, the incidence of stroke in China is increasing at an annual rate of $8.7 \%$ [3]. The nationwide annual cost for the treatment of cerebrovascular disease is more than 10 billion yuan, coupled with indirect economic losses of nearly 20 billion yuan [4]. Various health education measures have been undertaken to raise public awareness of stroke-related knowledge to reduce the incidence, mortality, and disability rates of stroke [5]. However, the level of understanding about stroke warning symptoms and first aid systems among community residents was generally low [6-8]. This study investigated the ability residents to identify the warning symptoms of stroke and the awareness of first aid and the effect of strengthening health education on stroke recognition among community residents. Herein, we aimed to investigate the current status and problems of community stroke prevention and to strengthen the publicity of the impact of stroke-related knowledge on community residents' stroke recognition, to propose and implement a new community stroke prevention service model to effectively reduce community stroke incidence.

\section{Methods}

\section{Sampling}

We conducted a survey of residents of nine communities of Jinjiang District, Chengdu, from February 2017 to February 2019 (including Chunxi, Yanshikou, Niushikou, Hongsha, Jinjiang, Lianxin, Wanke, Quan subtree, Daci temple). According to the method of estimating the minimum sample size of qualitative data recommended by Chinese Residents of Nutrition and Health Survey in 2002, 1800 households in Jinjiang District, the center of Chengdu with a permanent population of 690,400, were randomly selected. A cluster sampling method was adopted, with sampling of 200 households in each community according to the residence number. The participants were permanent residents of the community (The inclusion criteria were aged $\geq 18$; household registration was required to be considered a local, and the residents should have lived in the locality for more than 2 years).

\section{Survey contents}

Using an epidemiological investigation, combined with the literature reports from China and abroad [1-3, 5-9], a questionnaire on stroke-related knowledge was designed to conduct a cluster sampling survey among nine community residents in Jinjiang District, Chengdu. The questionnaire had 21 questions, which contained 4 main sections:

(1) Respondents' demographic details such as sex, age, ethnicity, educational level, monthly household income, and health insurance.

(2) Respondents' understanding of stroke risk factors (including high blood pressure, hyperlipidemia, diabetes, heart disease, drinking, smoking, stroke, obesity, age, genetic factors, atherosclerosis, vascular stenosis, lack of exercise, blood viscosity and etc).

(3) Respondents' recognition of stroke warning signs [5 "Suddens," including (i) sudden difficulty in speaking, understanding, or slurred speech, (ii) sudden blurred vision in one or both eyes, (iii) sudden severe headache with unknown cause, (iv) sudden dizziness, difficulty in walking, loss of balance or co-ordination, and (v) sudden numbness or weakness of the face and/or limb(s) on one side of the body]. The method of rapid identification of stroke involves applying the acronym "FAST" which means numbness or weakness on one side of the Face, numbness or weakness in the Arm, Speech or understanding difficulties and Time to call).

(4) Respondents' awareness of the first-aid system to sudden symptoms of stroke. Respondents were asked the questions: If you are sure that someone is having a stroke, what will your first reaction be? (i) drive to hospital, (ii) call for doctor, (iii) call for 120; (iv) call for family. We aimed to carry out stroke health education activities with the theme of "understanding stroke" and evaluate the effect. Stroke knowledge was publicized in a variety of ways, including: (1) designing and making short videos which neurologists explained the risk factors of stroke, its prevention and treatment, and the description of the main symptoms and signs of stroke. The session on the first aid after the onset of stroke emphasized the importance of making an emergency call (120, in China), and the harm of delayed treatment. Stroke survivors were also invited to talk about their personal experience. We used television, the Internet, WeChat, magazines, and other media channels for publicity. (2) We produced a pamphlet on stroke health education to be distributed to all families in the community, and produced posters of stroke-related knowledge to display in public places in the community. The duration of intensive stroke education activity was 1 year. All the participants received health information from all or some of the media mentioned. The media platforms contained the same health information. We provided 
information pamphlets to the participants and encouraged them to take the pamphlet home. The level of community stroke awareness was investigated before and after the activity, and the effect of intensive publicity was evaluated. The main evaluation indicators were the proportion of residents that accepted stroke-related knowledge due to the publicity, and the change of residents' recognition of stroke-related knowledge (stroke risk factors, stroke symptoms and signs, stroke and the treatment of specific symptoms). Face-to-face interviews were conducted by uniformly trained investigators.

\section{Data collection}

Data were collected via a questionnaire on community residents' stroke-related knowledge. The contents mainly included: (1) the general data of the participants; (2) stroke-related knowledge before and after the intensive publicity: stroke risk factors, warning symptoms, treatment measures of sudden symptoms, determination of post-stroke treatment.

\section{Statistical analysis}

After sorting out the data processing and survey data, the data were entered into the EPIDATA database and then imported into SPSS version 20 (IBM Corp., Armonk, NY, USA) for statistical analysis. Descriptive statistical analysis was used to assess the general characteristics of respondents, identify stroke-related risk factors, identify warning symptoms of stroke, and cope with stroke warning symptoms. Chi-square test was used to analyze the general characteristics of residents before and after intensive education and the residents' knowledge of stroke-related knowledge before and after intensive education. $P$ value less than 0.05 was regarded as statistically significant.

\section{Results}

\section{Demographic characteristics of the respondents}

A total of 1685 respondents completed the questionnaires, with the response rate of $93.6 \%$. Of the 1685 respondents, 768 were males (45.6\%) and 917 females (54.4\%), with an average age of $50.5 \pm 16.2$ (range, 1892) years. Demographic details are as shown in Table 1.

\section{Relationship between the number of stroke risk factors and stroke risk recognition}

The participants were assessed for the presence of risk factors (Table 2). The awareness level of stroke risk among community residents was $11.4 \%$. Only $40.3 \%$ of participants with three or more risk factors were aware of the risk of stroke. One hundred and fifty-four participants $(9.1 \%)$ could correctly identify 1 stroke risk factor, and $132(7.8 \%)$ could correctly identify 2 stroke risk
Table 1 Demographic data of the respondents $(N=1685)$

\begin{tabular}{|c|c|c|}
\hline & Number of Respondents & $\%$ \\
\hline \multicolumn{3}{|l|}{ Gender } \\
\hline Male & 768 & 45.6 \\
\hline Female & 917 & 54.4 \\
\hline \multicolumn{3}{|l|}{ Age $(y)$} \\
\hline $18-36$ & 399 & 23.7 \\
\hline $37-55$ & 591 & 35.1 \\
\hline $56-74$ & 575 & 34.1 \\
\hline$\geq 75$ & 120 & 7.1 \\
\hline \multicolumn{3}{|l|}{ Ethnicity } \\
\hline Han & 1668 & 99.0 \\
\hline Other & 17 & 1.0 \\
\hline \multicolumn{3}{|l|}{ Marital status } \\
\hline Unmarried & 196 & 11.6 \\
\hline Married or cohabiting & 1347 & 79.9 \\
\hline Divorce or separation & 54 & 3.2 \\
\hline Bereavement & 88 & 5.2 \\
\hline \multicolumn{3}{|l|}{ Educational level } \\
\hline Primary school or less & 182 & 10.8 \\
\hline Middle school & 416 & 24.7 \\
\hline High school/technical school & 594 & 35.3 \\
\hline College or more & 493 & 29.3 \\
\hline \multicolumn{3}{|l|}{ Health insurance } \\
\hline Yes & 1567 & 93.0 \\
\hline No & 118 & 7.0 \\
\hline \multicolumn{3}{|l|}{ Smoke } \\
\hline Yes & 476 & 28.2 \\
\hline No & 1209 & 71.8 \\
\hline
\end{tabular}

factors. One hundred and thirty-three participants (7.9\%) were able to identify at least 3 stroke risk factors. Also, 1164 participants (69.1\%) could not correctly identify any risk factors for stroke, of which 1061 cases (91.2, $63.0 \%$ of the total) could not provide any answer. Of the 1685 subjects, 922 (54.7\%) that did not know which part of the body was affected by stroke, only 699 (41.5\%) knew that stroke affected the brain, and 17 (1.0\%) believed that stroke affected the heart. Forty-seven participants $(2.8 \%)$ believed that stroke affected other parts (such as the hands, feet, cervical vertebrae, etc.).

\section{Recognition of stroke warning symptoms among participants}

The recognition rate of stroke warning symptoms among community residents was 29.8-59.5\% (Table 3). Among them, the recognition rate of common stroke symptoms such as limb weakness, language disorder, and balance disorder, was more than $50 \%$. For the other 
Table 2 Cognition of stroke risk factors among respondents

\begin{tabular}{lll}
\hline Risk factor & N & (\%) \\
\hline High blood pressure & 385 & 22.8 \\
Hyperlipidemia & 188 & 11.2 \\
Diabetes & 170 & 10.1 \\
Heart disease & 125 & 7.4 \\
Unhealthy lifestyle & 95 & 5.6 \\
Drinking & 90 & 5.3 \\
Smoking & 88 & 5.2 \\
Stroke & 72 & 4.3 \\
Obesity & 47 & 2.8 \\
Age & 31 & 1.8 \\
Genetic factors & 26 & 1.5 \\
Atherosclerosis & 19 & 1.1 \\
Vascular stenosis & 11 & 0.7 \\
Lack of exercise & 11 & 0.7 \\
Blood viscosity & 9 & 0.5 \\
Gender & 4 & 0.2 \\
False & & \\
Emotional & 33 & 2.0 \\
Overwork & 20 & 0.6 \\
Mental stimulation & 10 & \\
Other & 6 & \\
\hline
\end{tabular}

two relatively uncommon symptoms, the rate of recognition of severe headaches, including blurred monocular or binocular vision and no known cause, was only about $29.8 \%$. In addition, more than $25 \%$ considered shortness of breath, chest pain, and panic as symptoms of stroke.

\section{Recognition of stroke warning signs}

When faced with five sudden stroke warning signs, the proportion of participants who chose to dial 120 was lower, and the proportion that chose to go to the hospital was similar to that of those who chose to dial 120 . Nearly $10 \%$ of respondents chose others such as consulting a doctor, taking medicine, waiting, or observing (Table 4).

\section{Assessment after strengthening health education}

Before intensive publicity, there were 1685 respondents that completed the questionnaires. After intensive publicity, there were 1617 respondents that completed the questionnaires. There was no significant difference in the general situation of residents' cognition of stroke before and after intensive publicity and education (Table 5). After the onset of a stroke, the only appropriate response is to immediately activate emergency medical services (call 120, in China). After strengthening publicity and education, there was a significant improvement in the identification of stroke risk factors, stroke warning symptoms, and stroke management. The number of respondents who would dial 120 increased from 53.2 to 82.7\% (Table 6).

\section{Discussion}

The results of this study showed that the awareness level of stroke risk among community residents was $11.4 \%$. Only $40.3 \%$ of participants with three or more risk factors were aware of the risk of stroke. The results suggested that community residents had a low level of awareness of stroke risk. Among all the subjects, 1164 participants (69.1\%) could not correctly identify any risk factors for stroke, of which 1061 cases (91.2, 63.0\% of the total) did not provide any answer. However, a foreign demographic survey conducted in 2015 showed that $59.2 \%$ of the respondents were able to identify at least one stroke risk factor [10]. This study concluded that the community residents in Jinjiang District had a low awareness of stroke risk factors. Similar to some foreign survey, it is necessary to strengthen the popularity of the knowledge regarding stroke [11].

Of the 1685 participants, 922 (54.7\%) did not know which part of the body was affected by stroke, only $699(41.5 \%)$ knew that stroke affected the brain. Similar to the report of a foreign study, 35\% of respondents in this study knew that the organ in which stroke occurs was the brain [12]. These results suggest that community residents have poor knowledge of stroke-related symptoms.

Table 3 Cognition of stroke warning symptoms

\begin{tabular}{|c|c|c|c|}
\hline Warning symptoms & Yes & No & No idea or uncertain \\
\hline Difficulty speaking, articulating, or understanding & $953(56.6)$ & $149(8.8)$ & $583(34.6)$ \\
\hline Shortness of breath & $470(27.9)$ & $380(22.6)$ & 835 (49.6) \\
\hline Blurred vision in one eye or both eyes & $502(29.8)$ & $336(19.9)$ & $847(50.3)$ \\
\hline Severe headache of unknown cause & $612(36.3)$ & $208(12.3)$ & $865(51.3)$ \\
\hline Chest pain, panic & $533(31.6)$ & $335(19.9)$ & $817(48.5)$ \\
\hline Dizziness, difficulty walking, imbalance, or uncoordinated movements & $956(56.7)$ & $138(8.2)$ & $591(35.1)$ \\
\hline Numbness or weakness on one side of the face or limb & $1002(59.5)$ & $119(7.1)$ & $564(33.5)$ \\
\hline
\end{tabular}


Table 4 Cognition of stroke warning signs management in subjects [n (\%)]

\begin{tabular}{|c|c|c|c|c|c|}
\hline Warning signs & $\begin{array}{l}\text { Drive to } \\
\text { hospital }\end{array}$ & $\begin{array}{l}\text { Consulting a } \\
\text { doctor }\end{array}$ & $\begin{array}{l}\text { Call for } \\
120\end{array}$ & $\begin{array}{l}\text { Call family } \\
\text { members }\end{array}$ & Other \\
\hline Difficulty speaking, articulating, or understanding & $719(42.7)$ & $221(13.1)$ & $599(35.5)$ & $48(2.8)$ & $98(5.8)$ \\
\hline Shortness of breath & $604(35.8)$ & $180(10.7)$ & $769(45.6)$ & $37(2.2)$ & $95(5.6)$ \\
\hline *Blurred vision in one eye or both eyes & $577(34.2)$ & $270(16.0)$ & $680(40.4)$ & $66(3.9)$ & $92(5.5)$ \\
\hline *Severe headache of unknown cause & $723(42.9)$ & $136(8.1)$ & $709(42.1)$ & $40(2.4)$ & $77(4.6)$ \\
\hline Chest pain, panic & $652(38.7)$ & $167(9.9)$ & $702(41.7)$ & $45(2.7)$ & $119(7.1)$ \\
\hline $\begin{array}{l}\text { *Dizziness, difficulty walking, imbalance, or uncoordinated } \\
\text { movements }\end{array}$ & $708(42.0)$ & $128(7.6)$ & $736(43.7)$ & $47(2.8)$ & $66(3.9)$ \\
\hline *Numbness or weakness on one side of the face or limb & $745(44.2)$ & $117(6.9)$ & $697(41.4)$ & $47(2.8)$ & $79(4.7)$ \\
\hline
\end{tabular}

*five sudden stroke warning signs

The recognition rate of stroke warning symptoms among community residents was $29.8-59.5 \%$. Among them, the recognition rate of common stroke symptoms such as limb weakness, language disorder, and balance disorder, was more than $50 \%$. For the other two relatively uncommon symptoms, the recognition rate of severe headaches, including blurred monocular or binocular vision and no known cause, was only about $29.8 \%$. In addition, more than $25 \%$ considered shortness of breath, chest pain, and panic as stroke manifestations, suggesting that community residents still lack knowledge of stroke warning symptoms. A domestic survey on the recognition of stroke among community residents in Chongqing found that the recognition rate of stroke warning symptoms was $30.7-75.6 \%$ [9]. A study of 1472 respondents found that sudden headaches $(54.1 \%)$, vertigo (51.0\%), and dyslexia (44.3\%) were the most recognizable stroke warning symptoms [13].

When faced with five sudden stroke warning symptoms, most of the respondents chose to send the patients

Table 5 General situation of residents before and after intensive publicity

\begin{tabular}{|c|c|c|c|}
\hline & Before $(n=1685)$ & After $(n=1617)$ & $P$ \\
\hline Gender & & & 0.059 \\
\hline Male & 594 & 688 & \\
\hline Female & 920 & 929 & \\
\hline Age $($ mean $\pm S D)$ & $51.2 \pm 15.6$ & $53.4 \pm 16.6$ & 0.289 \\
\hline Nationality & & & 0.493 \\
\hline Ethnic Han & 1500 & 1598 & \\
\hline Other & 14 & 19 & \\
\hline Marital status & & & 0.418 \\
\hline Unmarried & 190 & 199 & \\
\hline Married or cohabiting & 1147 & 1258 & \\
\hline Divorce or separation & 67 & 62 & \\
\hline Bereavement & 110 & 98 & \\
\hline Degree & & & 0.274 \\
\hline Primary schools and below & 178 & 201 & \\
\hline Junior middle school & 397 & 407 & \\
\hline High school & 605 & 689 & \\
\hline College or above & 334 & 320 & \\
\hline Medical insurance & & & 0.803 \\
\hline Yes & 1407 & 1499 & \\
\hline No & 107 & 118 & \\
\hline Smoke & & & 0.306 \\
\hline Yes & 487 & 548 & \\
\hline No & 1027 & 1069 & \\
\hline
\end{tabular}


Table 6 Cognition of Stroke-related knowledge before and after intensive educational activities

\begin{tabular}{llll}
\hline & Before $(\boldsymbol{n}=\mathbf{1 6 8 5})$ & After $(\boldsymbol{n}=\mathbf{1 6 1 7})$ & $\boldsymbol{P}$ \\
\hline List the number of risk factors for stroke & $2.62 \pm 1.46$ & $4.18 \pm 2.07$ & $<0.001$ \\
Answer risk factors $\geq 3$ (\%) & $628(41.5)$ & $1009(62.4)$ & $<0.001$ \\
List the number of stroke warning signs & $1.28 \pm 1.25$ & $1.67 \pm 1.37$ & $<0.001$ \\
Know stroke warning symptoms $\geq 2$ & $542(37.3)$ & $779(48.2)$ & $<0.001$ \\
Answer 5 Suddens correctly & $138(8.2)$ & $269(16.6)$ & $<0.001$ \\
Answer "FAST" correctly & $119(7.1)$ & $306(18.9)$ & $<0.001$ \\
Call for 120 & $896(53.2)$ & $1338(82.7)$ & $<0.001$ \\
\hline
\end{tabular}

to hospital emergency department (by dialing 120 or going to the hospital themselves), but the proportion who preferred dialing 120 was lower. Similar to foreign reports, a survey conducted in New York found that 33.3$72.4 \%$ [14] of emergency calls were first made in the face of stroke warning symptoms, compared with 14-17.6\% in Michigan [15]. The results of the latest questionnaire survey on a small sample size abroad showed that $73.0 \%$ of the respondents chose to go to the hospital themselves and emergency calls comprised 43.8 and $62.6 \%$ [16], respectively. Calling the emergency system in time allows patients to arrive at the hospital more quickly and receive diagnosis and treatment (such as stroke green channels such as recombinant tissue plasminogen activator) than if they were sent to the hospital or via other transport routes.

In this study, we designed and produced television short films, animated short films, and distributed health pamphlets to explain the risk factors of stroke and their prevention and treatment measures. Through 1 year of intensive publicity and education, the residents' recognition of stroke-related knowledge (stroke risk factors, stroke symptoms and signs, stroke and the treatment of specific symptoms) was significantly improved. The number of respondents who dialed the 120-emergency system increased from $53.2 \%$ before publicity to $82.7 \%$. This study believes that strengthening publicity and education of stroke-related knowledge, and post-stroke treatment can significantly improve the cognition of stroke-related knowledge and enhance the community residents' awareness of the priority of dialing 120 after the onset of stroke. It can effectively reduce the prehospital delay in patients with stroke.

The shortcomings of this study are as follows: (1) the scope of the survey is limited to Jinjiang District of Chengdu, the sample size was small, and the results do not reflect the overall situation of Chengdu; (2) compared with an open-ended questionnaire, the closed questions used in this survey may result in a higher response rate in the evaluation of cognitive ability of stroke-related knowledge; and (3) the failure to ensure consistency of residents before and after participation in the intensive education.

\section{Conclusions}

In summary, the results of this community-based survey showed that the recognition of stroke warning symptoms of community residents in our city is low. In the face of sudden symptoms of stroke, even among those who have cognitive ability to all common stroke warning symptoms, the proportion that choose to dial 120 was also lower. Taking measures to further improve the recognition of stroke-related knowledge among community residents can enhance the awareness of community residents to call 120 after the onset of stroke and effectively reduce the pre-hospital delay among stroke patients.

\section{Acknowledgements}

We thank all the community residents in Jinjiang District of Chengdu City.

\section{Authors' contributions}

XMZ was responsible for the concept and design of the study, data collection, and the first draft of the paper and final manuscript. RX and JW were responsible for the concept and design of the study and the data analysis and interpretation. LYH was responsible for the data collection. All authors read and approved the final manuscript for publication.

\section{Funding}

This work is funding by the Health and family Planning Commission of Chengdu (2015009), which is not involved in the database management (collection, analysis, interpretation of data) and has no access to patient information. The funding body did not participate in designing the study or writing the manuscript. The study protocol has undergone peer-review process by the funding body.

\section{Availability of data and materials}

The datasets used and/or analyzed during the current study are available from the corresponding author on reasonable request.

Ethics approval and consent to participate

We obtained ethical approval for this study from the Medical and Health Research Ethics Committee in Second People's Hospital of Chengdu. Written informed consent was obtained from all study participants.

Consent for publication

Not applicable.

Competing interests

The authors declare they have no competing interests. 
Received: 2 November 2019 Accepted: 5 October 2020

Published online: 12 October 2020

\section{References}

1. Ma Y, Liu Y, Fu HM, et al. Evaluation of admission characteristics, hospital length of stay and costs for cerebral infarction in a medium-sized city in China. Eur J Neurol. 2010;17:1270-6.

2. Heron G, Wenzhi W. Advances in epidemiology of cerebrovascular diseases. Chin J Neurol. 2015;48:337-3.

3. Zhao D, Liu J, Wang W, et al. Epidemiological transition of stroke in China: twenty-one-year observational study from the Sino-MONICA-Beijing project. Stroke. 2008;39:1668-74.

4. Yu Y, Hu J, Efird JT, et al. Social support, coping strategies and healthrelated quality of life among primary caregivers of stroke survivors in China. J Residents Nine Commun Jinjiang Nurs. 2013:22:2160-71.

5. Lundelin K, Graciani A, García-Puig J, Guallar-Castillón P, Taboada JM Rodríguez-Artalejo F, et al. Knowledge of stroke warning symptoms and intended action in response to stroke in Spain: a nationwide populationbased study. Cerebrovasc Dis. 2012;34:161-8.

6. Kamran S, Bener AB, Deleu D, Khoja W, Jumma M, Al Shubali A, et al. The level of awareness of stroke risk factors and symptoms in the Gulf cooperation council countries: gulf cooperation council stroke awareness study. Neuroepidemiology. 2007;29:235-42.

7. Schneider AT, Pancioli AM, Khoury JC, Rademacher E, Tuchfarber A, Miller R, et al. Trends in community knowledge of the warning signs and risk factors for stroke. JAMA. 2003:289:343-6.

8. Chhabra M, Gudi SK, Rashid M. Rohit, Sharma P, Sharma S, et al. assessment of knowledge on risk factors, warning signs, and early treatment approaches of stroke among community adults in North India: a telephone interview survey. J Neurosci Rural Pract. 2019:10:417-22.

9. Yang J, Zheng M, Cheng S, Ou S, Zhang J, Wang N, et al. Knowledge of stroke symptoms and treatment among community residents in Western urban China. J Stroke Cerebrovasc Dis. 2014;23:1216-24.

10. Ramírez-Moreno JM, Alonso-González R, Peral-Pacheco D, Millán-Núñez MV, Aguirre-Sánchez JJ. Stroke awareness is worse among the old and poorly educated: a population-based survey. J Stroke Cerebrovasc Dis. 2015;24: 1038-46.

11. Menon B, Swaroop JJ, Deepika HKR, Conjeevaram J, Munisusmitha K. Poor awareness of stroke--a hospital-based study from South India: an urgent need for awareness programs. J Stroke Cerebrovasc Dis. 2014;23:2091-8.

12. Al Shafaee MA, Ganguly SS, Al Asmi AR. Perception of stroke and knowledge of potential risk factors among Omani patients at increased risk for stroke. BMC Neurol. 2006;6:38.

13. Alhazzani AA, Mahfouz AA, Abolyazid AY, Awadalla NJ, Ahmed RA, Siddiqui $A F$, et al. Awareness of stroke among patients attending primary healthcare services in Abha, southwestern Saudi Arabia. Neurosciences (Riyadh). 2019; 24:214-20.

14. Jurkowski JM, Maniccia DM, Dennison BA, Samuels SJ, Spicer DA. Awareness of necessity to call 9-1-1 for stroke symptoms, upstate New York. Prev Chronic Dis. 2008:5:A41.

15. Reeves MJ, Rafferty AP, Aranha AA, Theisen V. Changes in knowledge of stroke risk factors and warning signs among Michigan adults. Cerebrovasc Dis. 2008;25:385-91.

16. Yesilbalkan OU, Karadakovan A, Dogru BV, Akman P, Ozel E, Bozturk Y. Awareness of risk factors and warning signs of stroke among caregivers of patient with and not with stroke: results from questionnaire. J Pak Med Assoc. 2019:69:1114-8.

\section{Publisher's Note}

Springer Nature remains neutral with regard to jurisdictional claims in published maps and institutional affiliations.

Ready to submit your research? Choose BMC and benefit from:

- fast, convenient online submission

- thorough peer review by experienced researchers in your field

- rapid publication on acceptance

- support for research data, including large and complex data types

- gold Open Access which fosters wider collaboration and increased citations

- maximum visibility for your research: over $100 \mathrm{M}$ website views per year

At $\mathrm{BMC}$, research is always in progress.

Learn more biomedcentral.com/submissions 